Proceeding Paper

\title{
Field Spectroscopy Applied to the Kaolinite Polytypes Identification ${ }^{\dagger}$
}

\section{Andrea García-Vicente ${ }^{1, *}$, Adrián Lorenzo ${ }^{1}$, Juan Morales ${ }^{1}$, Emilia García-Romero ${ }^{2}$ and Mercedes Suárez ${ }^{1}$}

Citation: García-Vicente, A.; Lorenzo, A.; Morales, J.; García-

Romero, E.; Suárez, M. Field Spectroscopy Applied to the Kaolinite Polytypes Identification. Environ. Sci. Proc. 2021, 6, 16. https:// doi.org/10.3390/iecms2021-09353

Academic Editor: Paul Sylvester

Published: 25 February 2021

Publisher's Note: MDPI stays neutral with regard to jurisdictional claims in published maps and institutional affiliations.

Copyright: $(\odot) 2021$ by the authors. Licensee MDPI, Basel, Switzerland. This article is an open access article distributed under the terms and conditions of the Creative Commons Attribution (CC BY) license (http://creativecommons.org/licenses/by/4.0/).
1 Department of Geology, University of Salamanca, Plaza de la Merced, S/N, 37008 Salamanca, Spain; adrianlorenzo@usal.es (A.L.); juan.morales@usal.es (J.M.); msuarez@usal.es (M.S.)

2 Department of Mineralogy and Petrology, Complutense University of Madrid, C/ José Antonio Novais, 28014 Madrid, Spain; mromero@geo.ucm.es

* Correspondence: andrea_gar@usal.es

† Presented at the 2nd International Electronic Conference on Mineral Science, 1-15 March 2021; Available online: https://iecms2021.sciforum.net/.

\begin{abstract}
A detailed characterization of a group of kaolin samples rich in some minerals of the kaolinite group was done. The mineralogical and structural characterization was conducted by X-ray diffraction (XRD) together with the study of the spectroscopy response in visible-near infrared and short wave (VNIR-SWIR), and the main objective was the determination of kaolinite polytypes. The XRD patterns group the samples according to the kaolinite polytype into five kaolinites, two dickites and six halloysites. Diagnostic peaks for kaolinite, dickite polytypes and halloysite were identified in the spectra and in the second derivative of the SWIR region. The position and intensity of the peaks in the second derivative were statistically treated with the aim of classifying the spectra according to the polytype. In good agreement with the XRD results, the statistical analysis of the spectroscopic data, both by cluster analysis and by principal components analysis, allows an unequivocal classification of the samples according to the polytype from their VNIR-SWIR spectra.
\end{abstract}

Keywords: kaolinite polytypes; kaolinite; dickite; halloysite; VNIR-SWIR

\section{Introduction}

Kaolin is the rock formed mainly by minerals of the kaolinite group, which includes kaolinite and its polytypes, nacrite and dickite, as well as halloysite. They are characterized by structures based on the stacking of 1:1 layers formed by one tetrahedral and one octahedral sheet. Kaolinite, nacrite, and dickite are planar, while halloysite has a nonplanar rolled structure [1]. Kaolinite and its polymorphs belong to the group of 1:1 dioctahedral phyllosilicates, where only two of every three octahedral sites around each hydroxyl are filled.

The lateral dimensions of the tetrahedral sheet are usually larger than those of the octahedral sheet. Layer distortion thus originated from the requirement of matching the tetrahedral and octahedral sheets causes the polymorphysm [2]. Kaolinite, dickite, and nacrite attend to the same structural formula: $\mathrm{Si}_{2} \mathrm{Al}_{2} \mathrm{O}_{5}(\mathrm{OH})_{4}$. The poor structural order commonly observed in kaolin minerals can be explained in terms of a series of stacking faults or defects along the $c$-axis. This results in a variety of ordered and disordered polytypes [3-8].

In halloysite, there is a displacement respect to the crystallographic $x$ and $y$ axes, and $c$ parameter varies depending on whether it is halloysite (hydrated) or metahalloysite (dehydrated), with a structural formula of $\mathrm{Si}_{2} \mathrm{Al}_{2} \mathrm{O}_{5}(\mathrm{OH})_{4} \cdot \mathrm{nH}_{2} \mathrm{O}$ [9]. Hydrated halloysite has a kaolinite-like structure, except for a layer of water that is hydrogen bonded to the sheet. 
The mineralogical and structural characterization was conducted by X-ray diffraction (XRD) together with visible-near infrared and short-wave spectroscopy (VNIR-SWIR), with main objectives the mineralogical identification and determination of kaolinite polytypes as well as its analysis and classification through spectral features.

\section{Materials and Methods}

A detailed characterization of kaolin was done. For this purpose, 13 samples with high purity were selected from a wider group of kaolin samples.

The identification of the different phases present in the kaolin samples from XRD and VNIR-SWIR measurements required a previous treatment. In the preparation of samples for both techniques, manual grinding was done in agate mortar until the powdered fraction was obtained. X-ray powder diffraction (XRD) measurements were carried out on a BRUKER D8 ADVANCE ECO diffractometer with theta-2theta configuration. BRUKER D8 ADVANCE is the X-ray diffraction service in the University of Salamanca. The identification of the different mineral phases was carried out by comparison with the patterns collected in the JCPDS file [10] using EVA and X'pert Highscore Plus software. Spectroscopic analysis was carried out in the near infrared and short-wave infrared, that is, in the range of wavelengths from $400 \mathrm{~nm}$ to $2400 \mathrm{~nm}$. ASD Field Spec 4 equipment was used that has a spectral resolution of $1 \mathrm{~nm}$, using Spectralon@ as a reflectance reference target. The spectra obtained were analyzed with the ViewSpecPro and Spectragryph 1.2 [11] software that allow the normalization of the curves and identification of discriminatory features.

\section{Results}

\subsection{X-ray Diffraction (XRD)}

All samples show the 060 reflection of phyllosilicates at $1.49 \AA$, characteristic of dioctahedral minerals, and at first glance the profile of a kaolinite with 001 reflection at $\sim 7.1$ $\AA$, but a detailed analysis of the XRD patterns allows identification of a difference in the peak position and intensity related to the different polytypes. According to them, 5 samples were classified as kaolinite, dividing in turn into ordered kaolinite (samples K18 and K33) and disordered kaolinite (samples K123, GEO, and SOC). The position of the basal reflection 001 corresponds to a slightly higher spacing in disordered kaolinite (7.17-7.18 $\AA$ ), while ordered kaolinite has the 001 reflection at $7.15 \AA$ [12]. It can be deduced that the samples belong to the kaolinite polytype, since up to 14 diagnostic reflections corresponding to kaolinite were identified and are clearly discriminatory from their polytypes, dickite and nacrite as well [13]. Values corresponding to d-spacing that appear in the samples and that discriminate kaolinite from its polytypes are: $4.47 \AA, 4.36 \AA, 4.18 \AA, 3.84 \AA$, $3.73 \AA, 2.75 \AA, 2.56 \AA, 2.34 \AA$, and $2.29 \AA$. Furthermore, diagnostic peaks were identified for ordered kaolinite, not founded in disordered kaolinite, in $4.13 \AA$, $3.84 \AA$, $3.73 \AA$, and $3.37 \AA$ (Figure 1).

Overall, DI20 and D.MEX samples were identified as dickite, with 001 reflection at $7.16 \AA$ [13]. Twelve diagnostic reflections were found in dickite: $7.16 \AA, 4.44 \AA, 4.36 \AA, 4.26$ $\AA, 4.12 \AA, 3.95 \AA, 3.79 \AA, 3.58 \AA, 3.42 \AA, 2.42 \AA, 2.32 \AA$ and $1.65 \AA$ (Figure 2).

Six samples (2WD, H12, H14, HBD, HLM, and HVA) correspond to halloysite polytype (not planar) [13]. These samples present basal reflection 001 located between 7.20-7.6 A depending on whether it is halloysite or metahalloysite (Figure 3). 


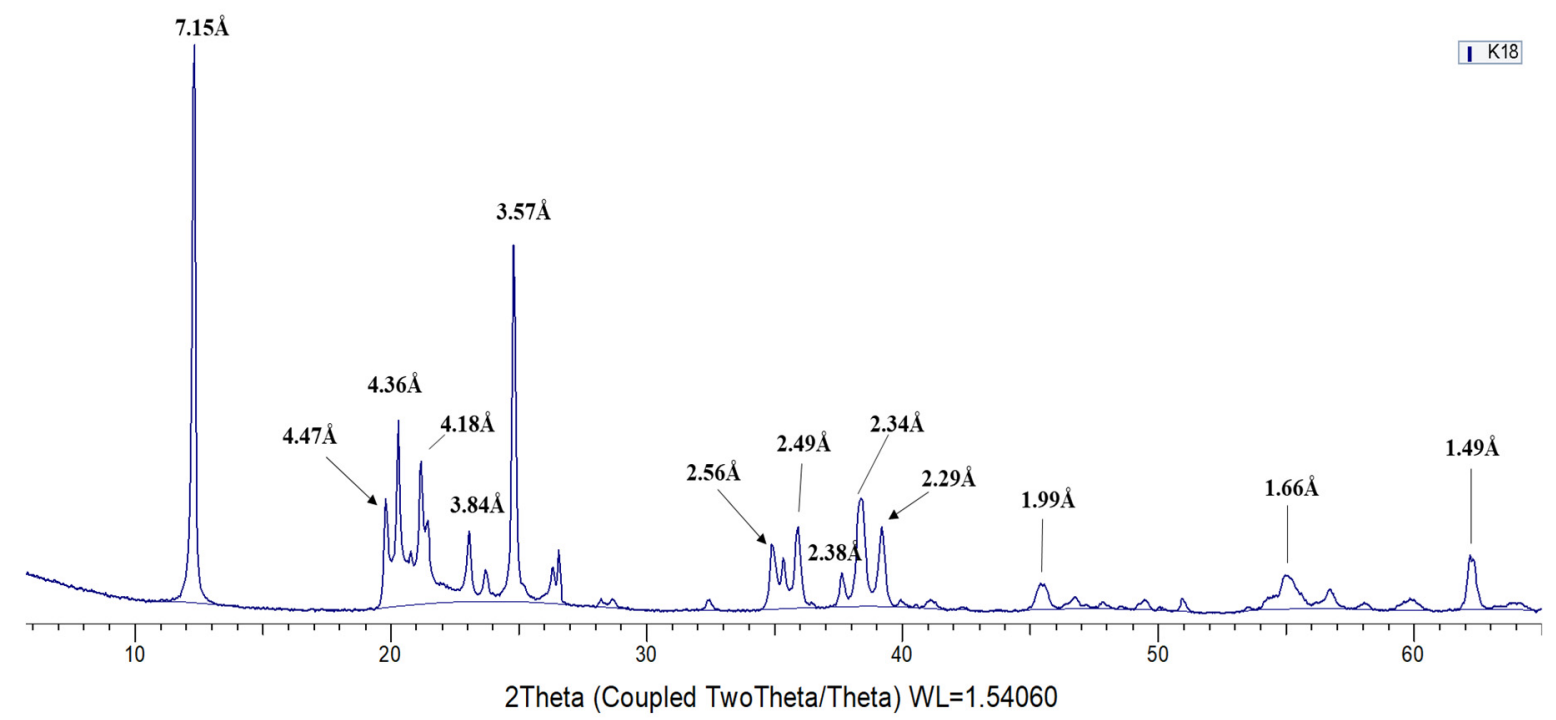

Figure 1. Diffractogram of an ordered kaolinite sample.

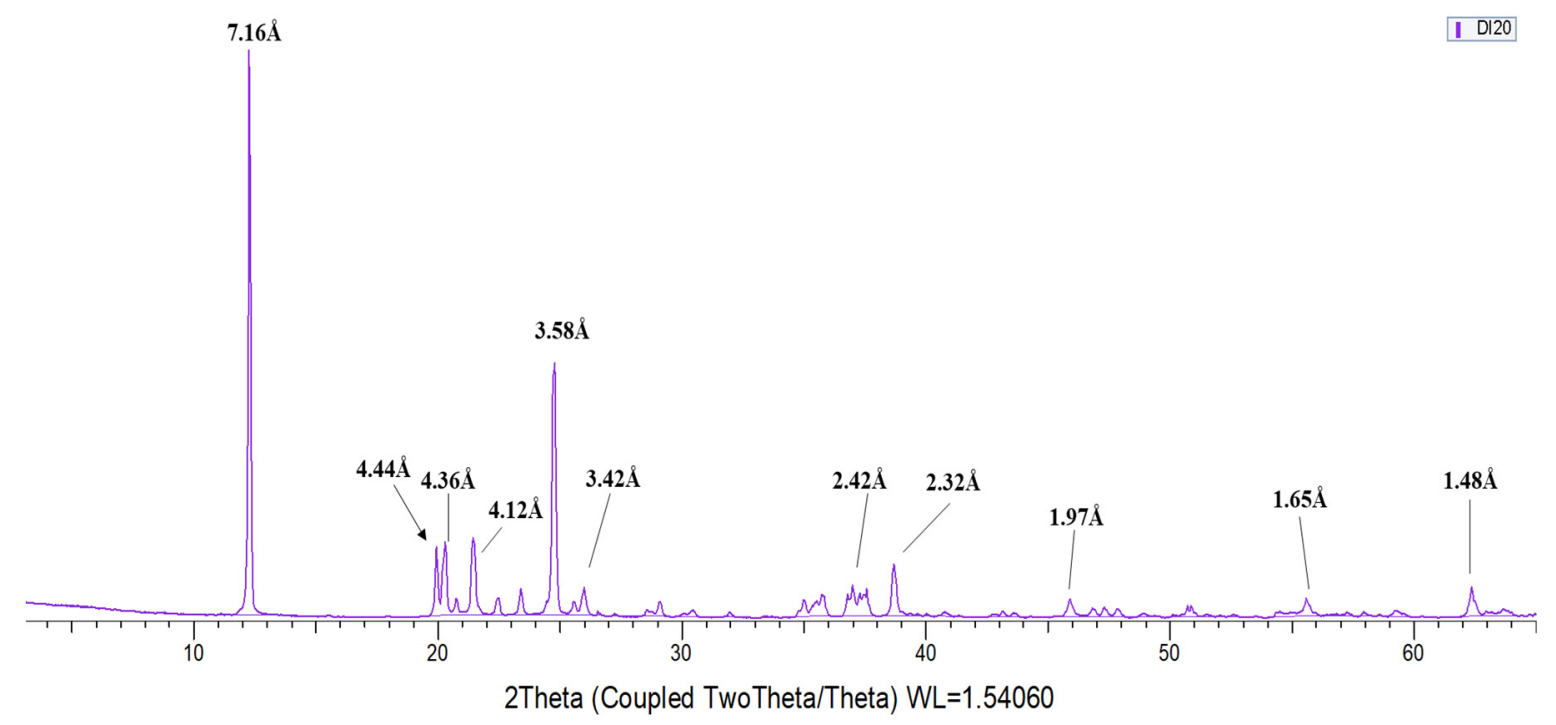

Figure 2. Diffractogram of dickite sample.

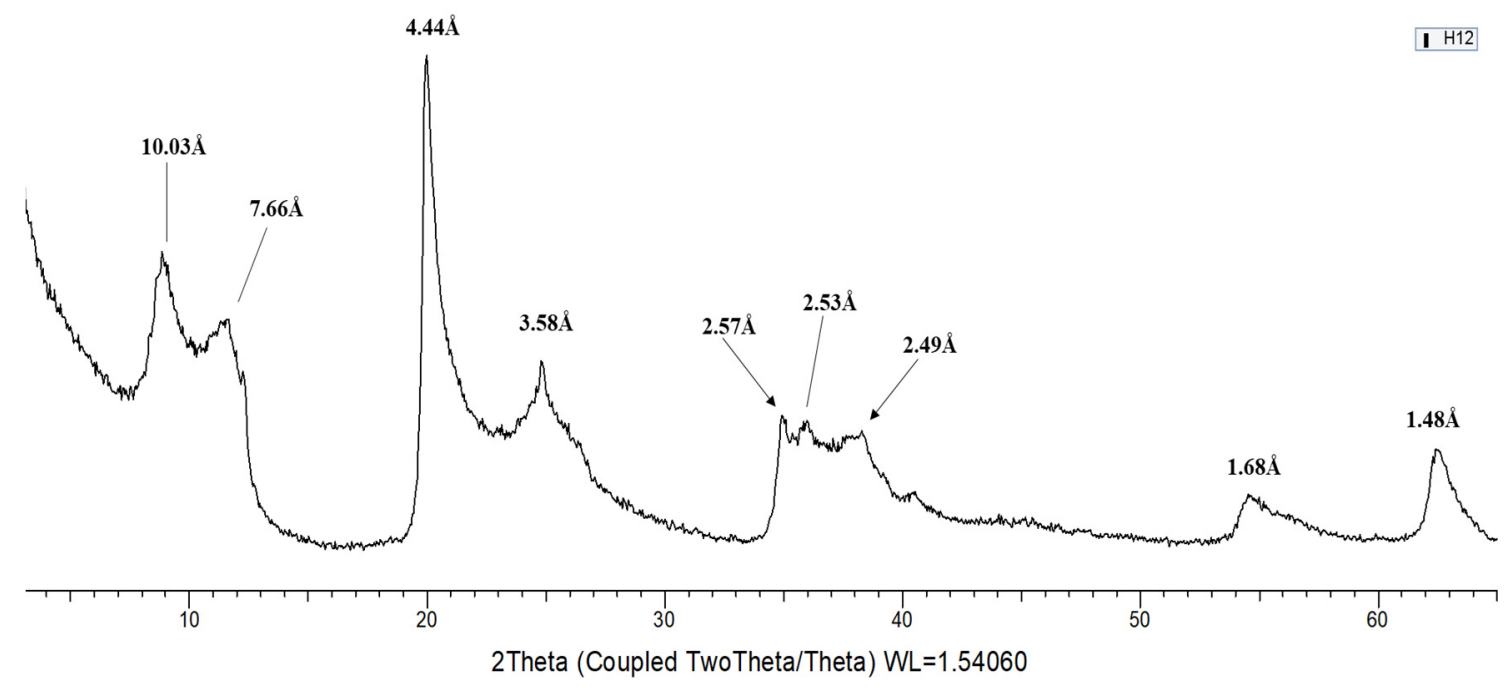

Figure 3. Diffractogram of halloysite sample. 
Figure 4 shows the cluster analysis done with the diagnostic reflections of all samples; Therefore, that classifies the samples into 3 groups corresponding to each of the polytypes. In turn, one of the groups corresponding to kaolinite is subdivided into ordered kaolinite and disordered kaolinite, according with the classification by XRD.

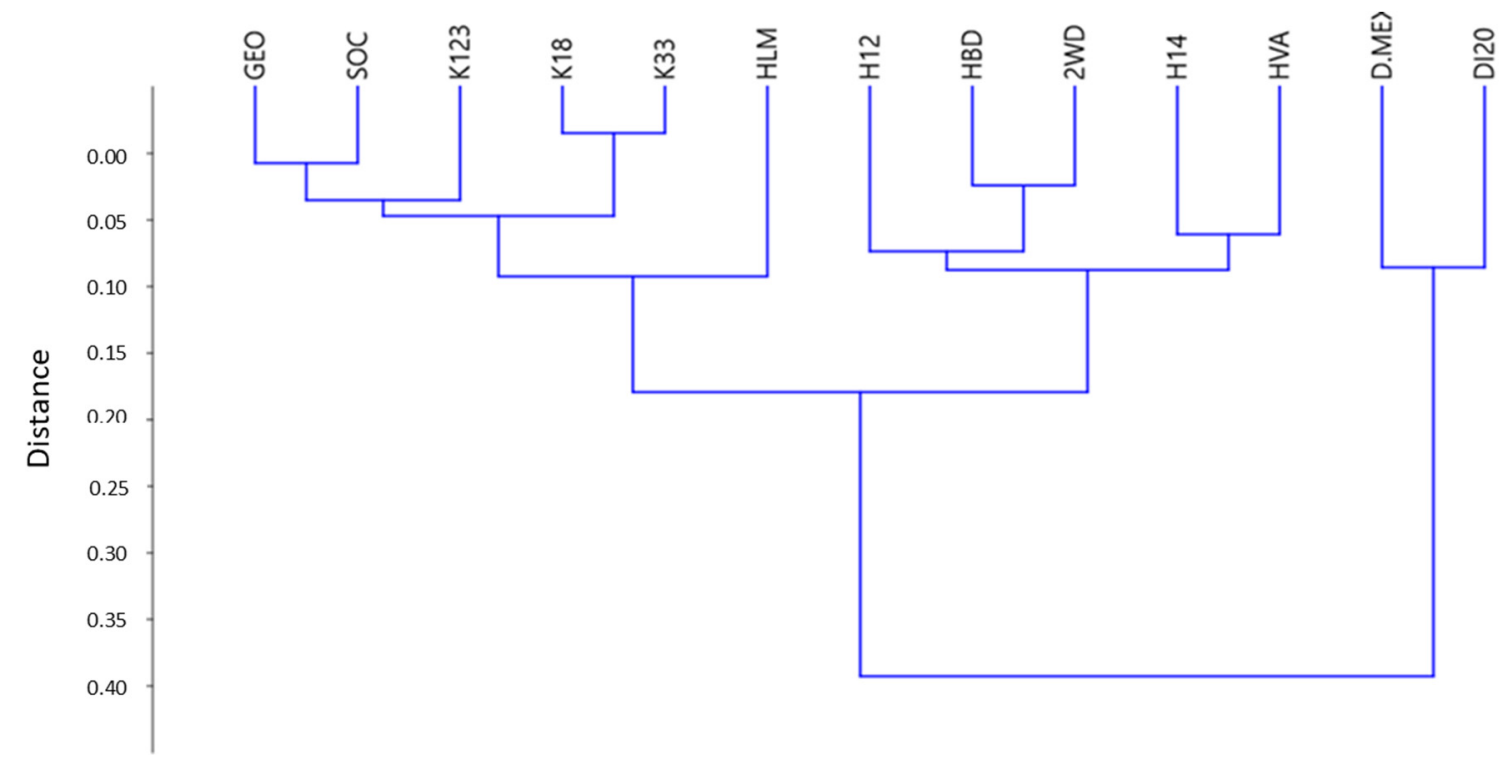

Figure 4. Cluster analysis of diffractograms that rank the minerals of the kaolinite group.

\subsection{Spectroscopy VNIR-SWIR}

The mineralogical identification was carried out considering the absorption features located in the spectra and comprised between $1150 \mathrm{~nm}$ and $2400 \mathrm{~nm}$, that is, in the near infrared and short wave.

Different phyllosilicates, such as kaolinite and its polytypes, dickite and halloysite, give rise to common absorption bands located in $1414 \mathrm{~nm}, 2114 \mathrm{~nm}, 2208 \mathrm{~nm}$, and 2383 by [14]. Other absorption bands were identified in $1272 \mathrm{~nm}, 1862 \mathrm{~nm}$, and $2240 \mathrm{~nm}$ in the reflectance spectrum (Figure 5). In the reflectance spectrum, the global reflectance was higher in the dickite and kaolinite spectra, thus decreasing for the halloysite spectra. In the latter, the depth and width of the absorption bands located in $1900 \mathrm{~nm}$ and $2200 \mathrm{~nm}$ increased (Figure 5). The second derivative of the spectra has allowed identification as peaks shoulder or inflexions of the absorption bands that could not be identified previously, also providing good results.

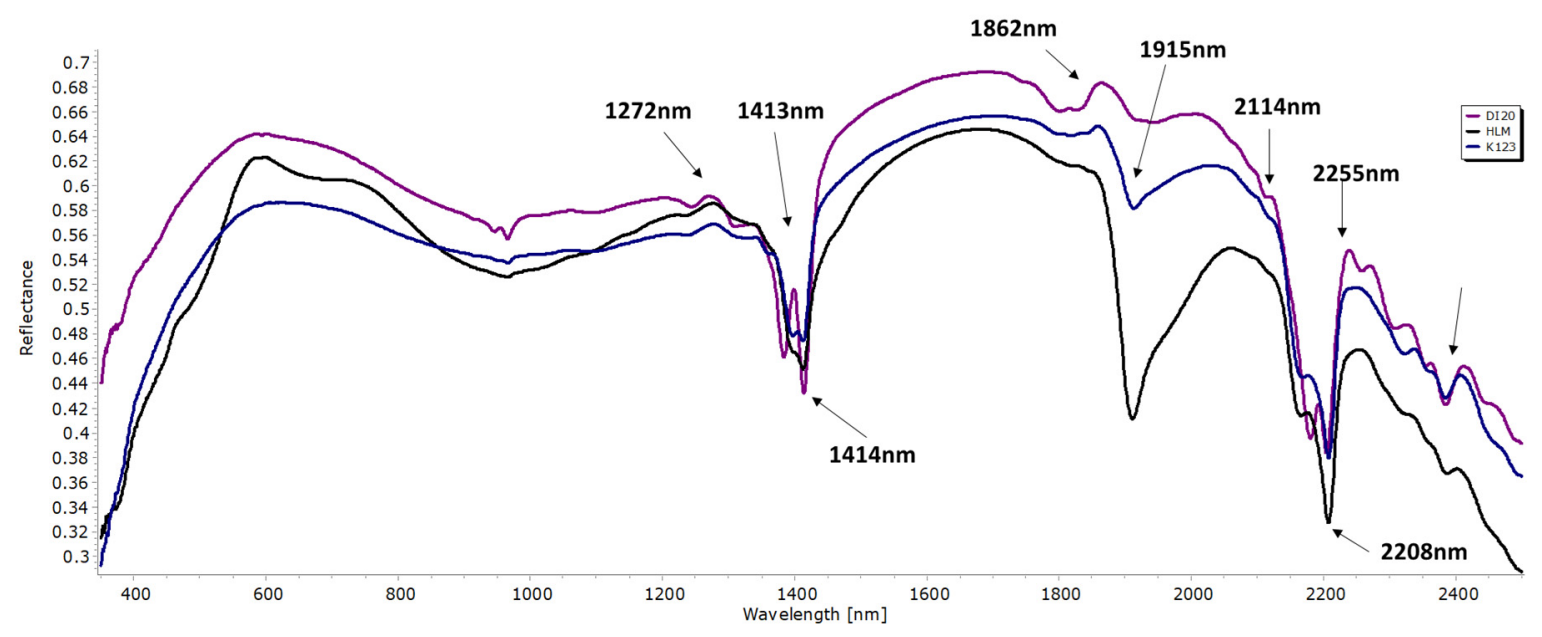

Figure 5. Reflectance spectra of kaolin samples. 


\subsubsection{Kaolinite}

In kaolinite with high crystallinity, four bands were found to be associated with the vibrational O-H process. Three absorption bands identified in $1379 \mathrm{~nm}, 1393 \mathrm{~nm}$, and 1345 $\mathrm{nm}$ correspond to inner-surface $\mathrm{OH}^{-}$groups [15]. In ordered kaolinite (blue in Figure 6), the near-infrared bands due to the combination of the stress and bending vibration modes of the $\mathrm{OH}^{-}$groups appear as a doublet at $2180 \mathrm{~nm}$ and $2190 \mathrm{~nm}$. The absorption band centered on $2208 \mathrm{~nm}$ is associated with the combination of the tension and bending modes of the inner-surface hydroxyl groups. In disordered kaolinite (brown in Figure 6), the shape of the $\mathrm{OH}^{-}$group bands is similar to the region of $\mathrm{O}-\mathrm{H}$ stress processes, reflecting the degree of disorder of kaolinite. Localized absorption bands were observed at $1340 \mathrm{~nm}, 1395$ $\mathrm{nm}$, and $1409 \mathrm{~nm}$ that are associated with stress processes in disordered kaolinite [15].

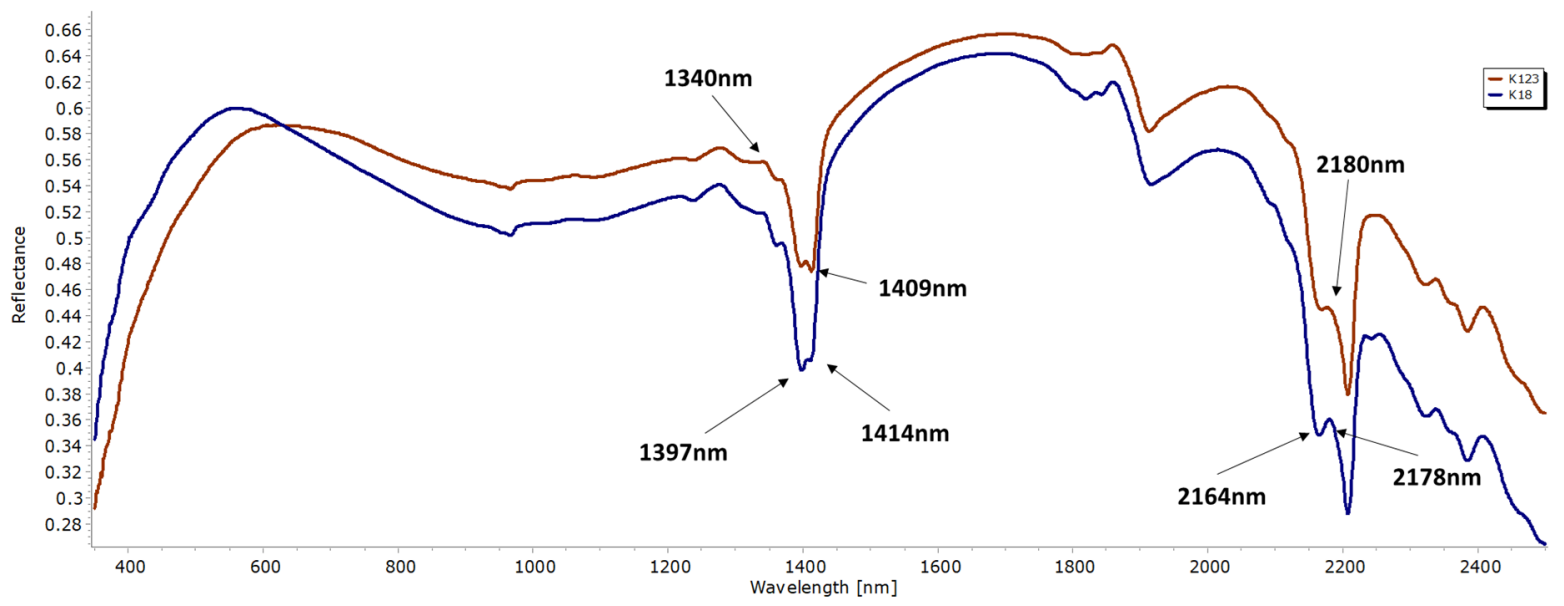

Figure 6. Reflectance spectra of kaolinite samples. Blue: ordered kaolinite. Red: disordered kaolinite.

\subsubsection{Dickite}

The reflectance spectrum of dickite is marked by the absorption band located in 1381 $\mathrm{nm}$, characteristic in this group for being in a lower position than kaolinite. Compared to kaolinite, dickite spectra show narrower and sharper bands in the region of $\mathrm{OH}^{-}$groups [14].The absorption band located at $1381 \mathrm{~nm}$ is related to the vibration of the inner surface $\mathrm{OH}^{-}$groups while at $1412 \mathrm{~nm}$ it corresponds to the bond vibration of the inner hydroxyl groups (Figure 7).

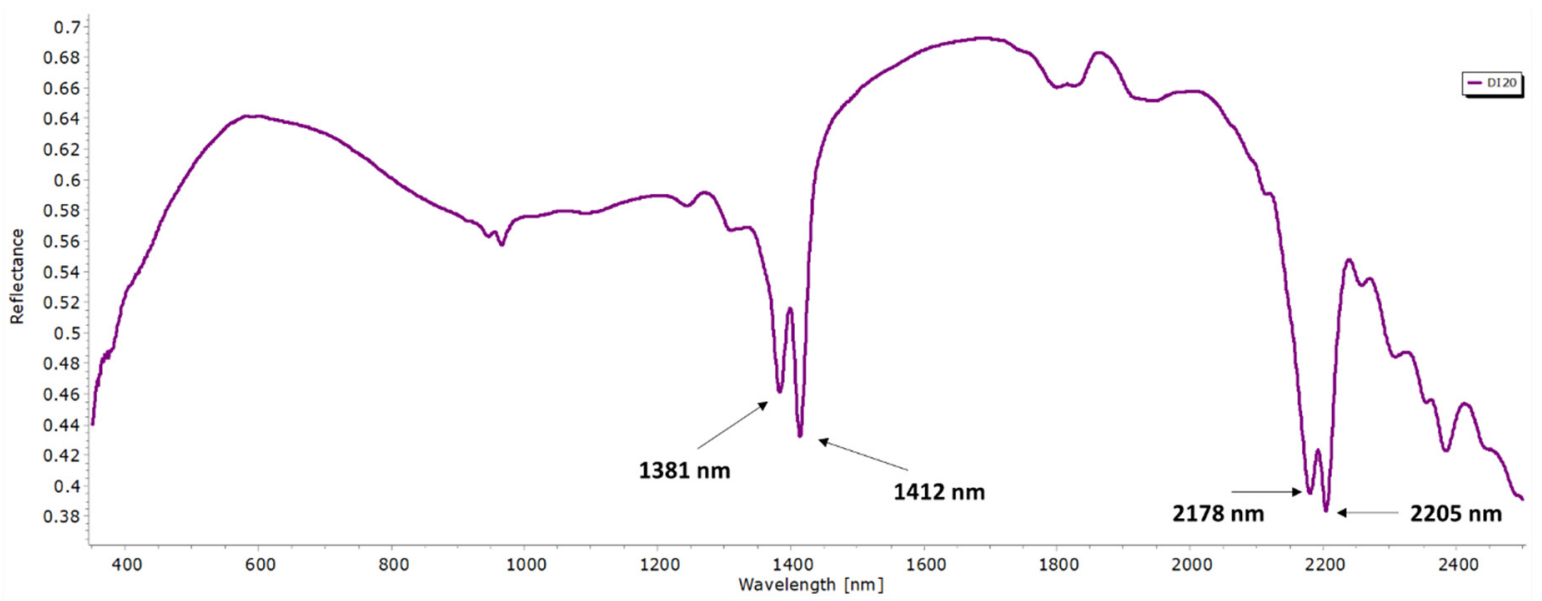

Figure 7. Reflectance spectra of dickite samples. 


\subsubsection{Halloysite}

Halloysite reflectance spectra are characterized by having absorption features marked in $1913 \mathrm{~nm}$ associated with the vibration of the O-H bond, committing the presence of water in the structure. At $1389 \mathrm{~nm}$, an absorption band appears involving the vibration of the inner-surface $\mathrm{OH}^{-}$groups' bond [15]. Halloysite spectra show a band labeled at $1414 \mathrm{~nm}$ related to the vibration of the bond of inner $\mathrm{OH}^{-}$groups (Figure 8).

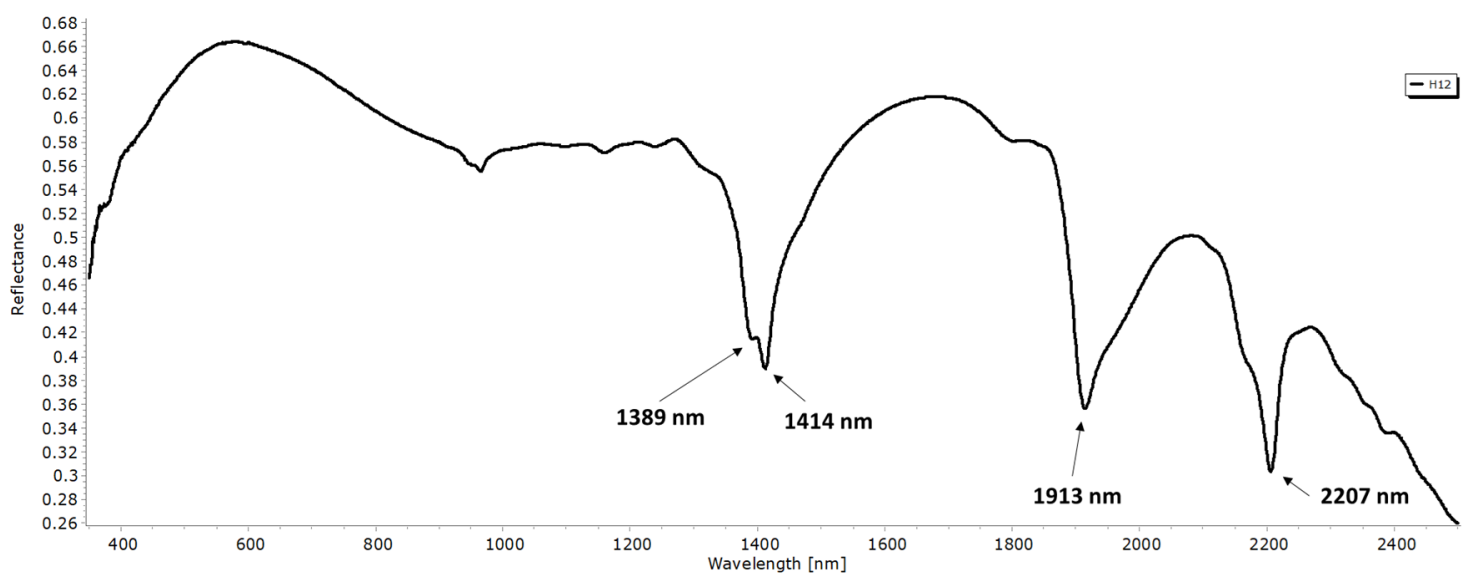

Figure 8. Reflectance spectra of halloysite.

\subsubsection{Statistical Treatment}

Intensities of the peaks of the second derivative were exported to Excel for subsequent statistical analysis. Correlation matrices allowed us to observe the relationship between kaolinite, dickite, and halloysite with respect to each of the wavelengths. Therefore, the wavelengths will be discriminatory for each polytype.

The cluster analysis was done with the intensities of the wavelengths according to the correlation matrix. Four groups were obtained with the wavelengths achieving the maximum possible homogeneity in each established group. In this way, a classification of the absorption bands that is better correlated with the minerals of the kaolinite group can be obtained.

\section{Conclusions}

- From the 13 samples studied, 5 have been identified as kaolinite, 2 as dickite and 6 as halloysite. Diagnostic XRD peaks for kaolinite, not found in dickite, appear in $4.47 \AA$, $4.36 \AA$, $4.18 \AA, 3.84 \AA, 3.73 \AA, 2.75 \AA$, and $2.29 \AA$. On the other hand, the diagnostic peaks of dickite, not found in kaolinite, appear in $4.44 \AA, 4.26 \AA, 4.12 \AA, 3.95 \AA, 3.79$ $\AA$, and $2.32 \AA$. Halloysite diagnostic reflections correspond to 7.20-7.6, $2.53 \AA$ and $1.68 \AA$.

- The main discriminatory absorption bands of the different polytypes are the following: $1397 \mathrm{~nm}, 1414 \mathrm{~nm}$, and $2208 \mathrm{~nm}$ with kaolinite, $1381 \mathrm{~nm}$ and $2178 \mathrm{~nm}$ with dickite; and finally, $1913 \mathrm{~nm}$ and $2138 \mathrm{~nm}$ with halloysite.

- Groups of diagnostic peaks for kaolinite, dickite, and halloysite polytypes were identified in the VNIR-SWIR spectrum and, in good agreement to XRD mineralogical identification, allow an unequivocal classification of kaolinite polytypes.

Author Contributions: All authors have contributed both to the obtention and discussion of the results. All authors have read and agreed to the published version of the manuscript.

Funding: This research was funded by the Spanish Ministerio de Ciencia e Innovación, grant number PID2019-106504RB-I00.

Institutional Review Board Statement: Not applicable. 
Informed Consent Statement: Not applicable.

Data Availability Statement: The data that support the findings of this study will be made available by the corresponding author (A.G.-V), upon reasonable request.

Conflicts of Interest: The authors declare no conflict of interest.

\section{References}

1. Guggenheim, S.; Adams, J.M.; Bain, D.C.; Bergaya, F.; Brigatti, M.F.; Drits, V.A.; Formoso, M.L.L.; Galán, E.; Kogure, T.; Stanjek, H. Summary of recommendations of Nomenclature Committees relevant to clay mineralogy: Report of the association Internationale pour l'Etude des Argiles (AIPEA) Nomenclature Committee for 2006. Clays Clay Miner. 2006, 54, 761-772.

2. Ross, C.S.; Kerr, P.F. The kaolin minerals. U. S. Geol. Surv. Prof. Pap. 1931, 165E, 151-176.

3. Zvyagin, B.B.; Drits, V.A. Interrelated features of structure and stacking of kaolin mineral layers. Clays Clay Miner. 1996, 44, 297-303.

4. Brindley, G.W.; Robinson, K. Structure of kaolinite. Nature 1945, 156, 661-663.

5. Brindley, G.W.; Robinson, K. Randomness in the structures of kaolinitic clay minerals. Trans. Faraday Soc. 1946, 42, $198-205$.

6. Bailey, S.W. Polymorphism of the kaolin minerals. Am. Mineral. 1963, 48, 1196-1209.

7. Bookin, A.S.; Drits, V.A.; Plançon, A.Y.; Tchoubar, C. Stacking faults in kaolin-group minerals in the light of real structural features. Clays Clay Miner. 1988, 37, 297-307.

8. Kloprogge, J.T. Spectroscopic Methods in the Study of Kaolin Minerals and Their Modifications; Springer: Berlin/Heidelberg, Germany, 2019; Volume 434.

9. Joussein, E.; Petit, S.; Churchman, G.J.; Theng, B.K.G.; Righi, D.; Delvaux, B. Halloysite clay minerals-A review. Clay Miner. 2005, 40, 383-393.

10. File, P.D. Joint Committee on Powder Diffraction Standards; ASTM: Philadelphia, PA, USA, 1967; pp. 9-185.

11. Menges, F. Spectragryph-Optical Spectroscopy Software. 2019. Available online: http://www.effemm2.de/spectragryph/ (accessed on 29 May 2020).

12. Bradley, W.F.; Grim, R.E.; Brown, G. X-ray Identification and Crystal Structures of Clay Minerals; Mineralogical Society, Clay Minerals Group: London, UK, 1951.

13. Moore, D.M.; Reynolds, R.C., Jr. X-ray Diffraction and the Identification and Analysis of Clay Minerals; Oxford University Press (OUP): Oxford, UK, 1989.

14. Hunt, G.R.; Ashley, R.P. Spectra of altered rocks in the visible and near infrared. Econ. Geol. 1979, 74, 1613-1629.

15. Hunt, G.R. Spectral signatures of particulate minerals in the visible and near infrared. Geophysics 1977, 42, 501-513. 